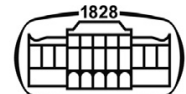

AKADÉMIAI KIADÓ

Journal of Psychedelic Studies

5 (2021) 3, 166-175

DOI:

10.1556/2054.2021.00191

(c) 2021 The Author(s)

\section{ORIGINAL RESEARCH} PAPER

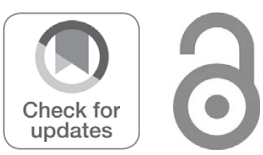

\title{
Philosophy and classic psychedelics: A review of some emerging themes
}

\section{CHRIS LETHEBY $^{1,2 *} \odot$ and JAIPREET MATTU ${ }^{3}$}

\author{
${ }^{1}$ Department of Philosophy, University of Western Australia, 35 Stirling Hwy, Crawley WA 6009, \\ Australia \\ ${ }^{2}$ Department of Philosophy, University of Adelaide, North Terrace, Adelaide SA 5005, Australia \\ ${ }^{3}$ Department of Philosophy, Rotman Institute of Philosophy, Western University, 7170 Western \\ Interdisciplinary Research Building, 1151 Richmond St., London, Ontario, N6A 5B8, Canada
}

Received: July 28, 2021 • Revised manuscript received: September 21, 2021 • Accepted: December 5, 2021

Published online: January 21, 2022

\begin{abstract}
Serotonergic (or "classic") psychedelics have struck many researchers as raising significant philosophical questions that, until recently, were largely unexplored by academic philosophers. This paper provides an overview of four emerging lines of research at the intersection of academic philosophy and psychedelic science that have gained considerable traction in the last decade: selfless consciousness, psychedelic epistemology, psychedelic ethics, and spiritual/religious naturalism. In this paper, we highlight philosophical questions concerning (i) psychedelics, self-consciousness, and phenomenal consciousness, (ii) the epistemic profile of the psychedelic experience; (iii) ethical concerns about the appropriate use of psychedelics; and (iv) whether spiritual or religious dimensions of psychedelic use are compatible with a naturalistic worldview.
\end{abstract}

\section{KEYWORDS}

philosophy, psychedelics, self-consciousness, epistemology, ethics

\section{INTRODUCTION}

Serotonergic (or "classic") psychedelics are the objects of renewed scientific interest. These psychoactive substances can induce dramatic changes to perception, cognition, and emotion, primarily via agonism of the serotonin-2a (5-HT2a) receptor in the brain. In a spate of recent trials, they have shown promise as treatments for psychiatric disorders (Wheeler \& Dyer, 2020), as agents that promote well-being in healthy volunteers (Gandy, 2019), and as research tools for probing the neural substrates of cognition and consciousness (Carhart-Harris, 2019).

Over the years, psychedelics have struck many researchers as raising significant philosophical questions (Osmond, 1971; Shanon, 2001; Smythies, 1953). Noted intellectuals have discussed some of these questions (Huxley, 1954/2009), in some cases even in the pages of philosophy journals (Smith, 1964). However, only in the second decade of the twenty-first century have psychedelics begun to receive detailed attention from those whose primary training and specialization is in academic philosophy.

In this paper we review four emerging lines of research at the intersection of academic philosophy and psychedelic science. The first concerns the use of psychedelic evidence in philosophical theorizing about the mind. Here, the most-discussed question is whether psychedelic research reveals the existence of totally selfless conscious states. The second concerns the epistemic status of the psychedelic state: Despite its misrepresentational components, might subjects gain genuine forms of knowledge from the psychedelic experience? The third line of research concerns ethical issues: Is it morally problematic to administer psychedelics if they pose epistemic risks? Does the therapeutic use of 
psychedelics require an "enhanced consent" process in order to be ethically justifiable? Might psychedelics constitute effective moral enhancement agents? The fourth, and final, line of research concerns religion and spirituality: Does psychedelic evidence reveal the existence of genuine forms of religious or spiritual practice that are compatible with a naturalistic worldview?

A note on method and scope is in order. We have made no attempt at a systematic literature search. These four lines of inquiry do not exhaust the interactions between philosophy and psychedelic research; they are simply the most prominent areas of interest to emerge in the academic literature over the past decade. This is a narrative review, and is not based on a formal literature search; nonetheless, we have applied certain exclusion criteria. We focus mainly on peer-reviewed scholarly work in English published from 2010 to 2020 inclusive. We restrict ourselves to work that is devoted primarily to addressing (a) distinctively philosophical questions (b) as they arise in relation to recent psychedelic research. Finally, we restrict ourselves to work discussing the "classic", $5-\mathrm{HT}_{2 \mathrm{~A}}$ agonist psychedelics such as LSD, mescaline, psilocybin, and DMT.

\section{MIND}

Perhaps the most obvious philosophical application of psychedelic research is as a source of evidence for the philosophy of mind. The recent interdisciplinary enterprise of philosophical psychopathology (Graham \& Stephens, 1994) is predicated on the idea that the study of atypical states of mind can inform philosophical theorizing in this domain. Psychedelics induce intense and unusual experiences which many volunteers rank among the most meaningful of their lives (Griffiths et al., 2006, 2016). It has been suggested repeatedly that psychedelics constitute a valuable tool for the investigation of mental phenomena, since, under conducive circumstances, they can reliably induce states of consciousness that otherwise occur only haphazardly, thereby facilitating disciplined and rigorous study of these states (Grof, 1975; Huxley 1954/2009).

\section{Selfless consciousness}

Of the many changes to consciousness that psychedelics induce, the one that has attracted most attention in recent philosophy is the profound alteration to self-consciousness known as ego dissolution (Nour, Evans, Nutt, \& CarhartHarris, 2016). Subjects administered moderate-to-high doses of psychedelics often report that the ordinary sense of self is radically altered or altogether absent. Some authors (e.g., Letheby \& Gerrans, 2017) have argued that such experiences suggest a metaphysically anti-realist view about the self. However, most discussion has focused on what such experiences may reveal about the relations between consciousness and self-consciousness. Might some psychedelic states constitute counterexamples to the influential thesis that phenomenal consciousness necessarily involves some form of self-consciousness? Millière (2017) calls this thesis the Self-Awareness Principle (SAP):

"(SAP) Necessarily, whenever one is in a conscious state, one is minimally self-aware” (p. 14).

Billon and Kriegel (2015) have discussed putative counterexamples to SAP such as "disowned" mental states occurring in depersonalization disorder (DPD). These authors concede that, in some such cases, the evidence for a total loss of self-consciousness or self-awareness is compelling; however, they suggest that in such cases, the relevant mental states may not, after all, be phenomenally conscious (Billon \& Kriegel, 2015). (Note: we use the terms "self-consciousness" and "self-awareness" interchangeably and in a purely phenomenological sense that is neutral on the metaphysics of the self.) Millière (2017) argues that this line of defence cannot work in relation to certain states of psychedelic ego dissolution. In some cases, he contends, the evidence for a total loss of self-consciousness is very strong-for example, some subjects are reluctant to use the first-person pronoun in their retrospective descriptions-yet "self-reports clearly converge in indicating that [ego dissolution] is a conscious experience. .. that is memorable" (Millière, 2017 p. 14). Similarly, Millière, Carhart- Harris, Roseman, Trautwein, and Berkovich-Ohana (2018) focus on experiences reported by those who smoke the intense, short-acting psychedelic 5MeO-DMT. Users of this substance often report an experience of emptiness, nothingness, or void, which would seem to lack self-consciousness entirely but clearly is a memorable conscious experience.

Thus, a psychedelic argument against SAP has been advanced in the literature. If Millière (2017) is correct, then the approach taken by Billon and Kriegel (2015) - arguing that the relevant mental states lack phenomenal consciousness-will not work as a response to this argument. However, other responses have been offered by proponents of SAP. One response appeals to the notion of for-me-ness, drawn from the phenomenological tradition in philosophy. For-me-ness is sometimes described as the most minimal form of self-consciousness possible. According to its proponents, it is not simply one content of consciousness among others, but an ineliminable structural feature of conscious experience as such:

\footnotetext{
"...the "me" of for-me-ness is not in the first instance an aspect of what is experienced but of how it is experienced; not an object of experience, but a constitutive manner of experiencing. To deny that such a feature is present in our experiential life, to deny the for-me-ness or mineness [sic] of experience, is to fail to recognize the very subjectivity of experience [...] once anything occurs consciously, it must be given to the subject and thus exhibit for-me-ness. In other words, the "me" of for-me-ness is not a separate and distinct item but rather a pervasive feature of experiential life as such" (Zahavi \& Kriegel, 2015, p. 38, emphasis in original).
}

Such philosophers argue that the presence of this phenomenological feature is revealed by a pervasive epistemic asymmetry: I enjoy a kind of direct access to my own experiences that is utterly unlike anyone else's access to 
those experiences. This, it is claimed, shows that these experiences are given first-personally to me, the subject of experience, and therefore exhibit for-me-ness. Henriksen and Parnas (2019) respond along these lines to Millière's (2017) psychedelic argument against SAP. According to Henriksen and Parnas, even psychedelic experiences featuring extreme disruptions to self-awareness are still "first-personally manifest to the subject of experience and not to anybody else" (2019, p. 15); thus, these experiences retain for-me-ness.

Letheby (2020) advances a psychedelic argument against SAP that is similar to that given by Millière and contends that the for-me-ness response (which he calls the Universalist Objection) will not work. Authors like Henriksen and Parnas (2019) infer the presence of for-me-ness, a putatively phenomenological feature, from the presence of an epistemic asymmetry: From the fact that I have a unique kind of direct access to my experiences, such authors infer that my experiences must possess some specific phenomenological feature. However, according to Letheby (2020), this sort of response is question-begging. Nobody denies the fact of epistemic asymmetry, but whether the presence of this asymmetry necessarily entails the presence of some phenomenological feature is precisely the point at issue. Letheby (2020) claims that proponents of for-me-ness are inconsistent in how they define this feature, and poses a dilemma: either it is a genuinely phenomenological feature, in which case some psychedelic experiences clearly lack it, or it is a mere matter of epistemic asymmetry, and therefore irrelevant to questions about self-consciousness.

The psychedelic argument against SAP has also been criticized by Sebastián (2020), who advocates a notion, similar to for-me-ness, which he calls perspectival first-personal (PFP) awareness. Sebastián agrees with Millière and Letheby that the putative universality of PFP awareness is subject to empirical test and could, in principle, be refuted by phenomenological reports of altered states. However, he does not think that the existing psychedelic evidence refutes SAP, for two reasons. The first is that extant descriptions of psychedelic ego dissolution (he contends) are ambiguous between two possibilities: (i) the experience was one of total ego-loss, i.e., it lacked all forms of self-consciousness, or (ii) the experience was one of total ego-expansion or unity, i.e., it retained a sense of self but lacked a sense of self/world boundaries. The second reason is that phenomenological reports may be subject to interpretive bias. Sebastián points out, first, that certain cultures with traditions of ritual psychedelic use do not emphasise experiences of ego dissolution, and second, that neo-Buddhist ideas about the nonexistence of the self or the "death of the ego" have strongly influenced conceptualizations of psychedelic experience in the popular Western imagination. As such, he recommends future trials with new, tailor-made psychometric instruments, and careful controls for cultural influence, in order to determine whether some psychedelic states really falsify SAP (Sebastián, 2020).

Another potential problem for the psychedelic argument against SAP concerns the status of retrospective phenomenological reports of totally selfless states. Metzinger (2003) has argued that such reports create a "performative self-contradiction", because (i) the content of such reports is that the self was absent from the earlier experience, but (ii) this is contradicted by a presupposition of giving a sincere retrospective autobiographical report: namely, that the self was present in the earlier experience. Fink (2020) considers several ways of interpreting such reports, and argues that on many interpretations, no contradiction arises. However, he ultimately agrees with Metzinger that a contradiction arises if such reports are taken to describe states of total ego dissolution. Similarly to Sebastián (2020), Fink suggests that states described as total ego dissolution might really be unitive experiences of ego expansion. On the other hand, Millière (2020) argues that there is no contradiction: the content of the relevant reports is that the earlier experience lacked self-awareness, a phenomenological feature, not that the metaphysical self or subject was absent. He considers a different construal of Metzinger's objection which focuses on the mechanisms of autobiographical and episodic memory, and argues that our best scientific understanding of these phenomena suggests there is no insurmountable obstacle to trusting reports of this kind.

In short, some reports of psychedelic experience seem to present counterexamples to the philosophical thesis that all conscious experiences are accompanied by some minimal form of self-consciousness. However, the interpretation of the thesis itself and of the relevant reports is highly contentious. It is safe to say that more research is required.

\section{Other issues in philosophy of mind}

The debate over ego dissolution and SAP is the most prominent, but not the only, discussion of psychedelic evidence in the philosophy of mind. The popular claim that the psychedelic state constitutes a "higher" state of consciousness has been scrutinised critically in light of recent work on levels and dimensions of consciousness (Bayne \& Carter, 2018; Fortier-Davy \& Millière, 2020). Other authors have discussed whether psychedelic evidence might favour certain metaphysical positions on the classical mind-body problem (Jones, 2019; Kastrup, 2016). In contrast, others have suggested that psychedelic evidence might aid ongoing efforts to solve the so-called "Hard Problem of Consciousness" within a physicalist framework (Brogaard \& Gatzia, 2016a), and explanations of key psychedelic phenomena have been offered in terms of empirically-based theories of phenomenal consciousness (Gallimore, 2015; Grinde \& Stewart, 2020; O'Brien \& Opie, 2015). Another project involves the use of conceptual tools from the phenomenological tradition in philosophy to analyse and describe the psychedelic state, thereby putatively advancing the project of classical phenomenology itself (Horváth, Szummer, \& Szabo, 2018; Szummer et al., 2017, 2019). Finally, Brogaard and colleagues have used data from psychedelic neuroscience to develop empirically-informed philosophical accounts of mental phenomena such as synaesthesia (Brogaard, 2013; 
Brogaard \& Gatzia, 2016b) and attention (Kentridge \& Brogaard, 2017).

\section{KNOWLEDGE}

Another line of inquiry concerns the epistemic status of the psychedelic experience: Does psychedelic administration reliably facilitate the acquisition of certain kinds of knowledge? Under conducive circumstances, psychedelics can induce mystical-type experiences which appear phenomenologically indistinguishable from those described by religious practitioners throughout the ages (Griffiths et al., 2006; Pahnke, 1963). As such, some have claimed that psychedelic subjects can gain direct knowledge of the existence of a cosmic consciousness or divine Ground of Being (Richards, 2015; Smith, 2000/2003). However, in recent years some philosophers have examined the epistemic status of the psychedelic experience within the confines of a naturalistic worldview that eschews such posits. Might psychedelic administration facilitate genuine knowledge acquisition, even if the natural world described by science is all that exists?

While his specific focus is ayahuasca, Shanon (2010) makes several proposals which might be applicable to other psychedelics too. First, he suggests that psychedelic users can gain psychological insights, becoming aware of facts about their own personality and behaviour, as well as gaining insights into how their minds work. Subjects often report such apparent insights, and there is some evidence that these correlate with reductions in psychiatric symptoms (CarhartHarris et al., 2018; Davis, Barrett, \& Griffiths, 2020). Shanon also suggests that subjects can gain psychological insights into others' minds, when psychedelics are taken in a group setting. On the first count, however, he does not consider the possibility that some apparent insights might be merely apparent. He does not offer an explicit argument for thinking that psychedelics induce genuine insights, rather than spurious insights that feel convincing (cf. CarhartHarris \& Friston, 2019; Jopling, 2001). He does suggest, however, that the accuracy of psychological insights concerning other people can and should be tested empirically (Shanon, 2010, p. 268).

Shanon also suggests that ayahuasca users can gain certain kinds of knowledge concerning the natural world and other forms of life. Here, he does not seem to be referring to the discovery of new empirical facts. Rather, he seems to have in mind something like what philosophers have called "new knowledge of old facts" (Nida-Rümelin \& Conaill, 2019):

"The following example of my own happened during an ayahuasca session held in a hut, in the midst of the Amazonian Forest, early in the morning. I was looking at the leaves of plants observing how they were directed towards the rays of the sun. I felt I was actually seeing the nurturing sustenance of the solar light. Have I obtained any "information" I had not known beforehand? I doubt it. But I was open to see the world in a new light, perhaps in the manner a poet or an artist may. As many have stated, a key function of paintings is to make people see things afresh, in a new light. Other cases pertaining to this category that I and my informants have experienced concerned the eternal cycles of life, life and death, social interaction and love, the harmonious being of animals in the wild and biological evolution" (Shanon, 2010., p. 268).

Shanon also notes that users of ayahuasca often start asking distinctively philosophical questions and espousing classic philosophical positions, even without any prior education in philosophy. In particular, he claims that ayahuasca intake leads users to adopt a consistent metaphysical worldview: an idealistic monism with a pantheistic flavour, similar to what Aldous Huxley dubbed the Perennial Philosophy. Shanon does not claim that ayahuasca users come to know the truth of this view through their experiences. He notes, however, that this striking cross-personal commonality requires explanation, and may tell us something important about the architecture of the mind (Shanon, 2010).

Shanon offers several other suggestions about types of knowledge gain that might occur during the ayahuasca experience. Some of these would seem to fall under the philosophical rubric of knowledge-how. For example, he observes that people who participate in ritual singing and dancing under ayahuasca seem to exhibit a remarkable degree of stamina and coordination. He also claims that, with repeated consumption, users may become skilled in "the very art of drinking ayahuasca" - an "artful skill in its own right” (Shanon, 2010, p. 272-273). Referring to the phenomenon of medical practitioners using ayahuasca to make diagnoses, Shanon argues that this practice is efficacious, but does not operate via the paranormal mechanisms that such practitioners posit; rather, the ayahuasca state allows practitioners to make better use of their existing specialist knowledge. Shanon also mentions enhancements to "wellbeing, overall comportment, and wisdom” (2010, p. 270) during the ayahuasca experience as putative epistemic benefits, and, finally, points out that simply by having extremely novel types of experiences, subjects are gaining new knowledge about their own consciousness.

This last point connects with a proposal made by Letheby (2015): that psychedelic experience allows subjects to gain knowledge by acquaintance with certain facts about their own minds. Russell (1910) originally defined knowledge by acquaintance as direct knowledge, with no representational mediation between the mind and the object of knowledge; however, Letheby adopts an intuitive understanding of this term. He points out that there are two facts about the mind that are easy to know indirectly, through others' testimony, but harder to know through one's own experience: first, that one's mind has vast potential that normally goes unrealized, including the potential for harmonious states of mystical wonder and joy, and, second, that one's ordinary sense of self is contingent and constructed, resulting from representational processes in the brain (Letheby, 2015). He cites evidence that brain activity under psychedelics becomes more disorderly or entropic 
(Carhart-Harris et al., 2014) due to the disruption of neural networks involved in self-representation. As a result, Letheby argues, many psychedelic users gain knowledge by acquaintance with these two facts.

Letheby (2015) also claims that psychedelic states can have indirect epistemic benefits via their apparent therapeutic effects. First, he points out that pathologies for which psychedelics show promise, such as depression and addiction, are characterised by cognitive rigidity (cf. CarhartHarris et al., 2014). Those who suffer from such conditions find it difficult to imagine other possibilities for themselves. Letheby cites research suggesting that psychedelics are therapeutic, in part, because they shake the brain out of its rut, allowing dysfunctional neural networks to be reset into a healthier configuration. He suggests that when this has lasting antidepressant or antiaddictive effects, it is likely to translate into an improved capacity to acquire modal knowledge-knowledge about possibility, necessity, impossibility, and so on-about one's own mind (Letheby, 2015). On this view, certain psychiatric patients suffer an epistemic deficit due to cognitive inflexibility; controlled psychedelic administration can alleviate the inflexibility and thereby remedy the deficit (Letheby, 2015).

Letheby (2016) also draws on Bortolotti's (2015, 2020) work on epistemic benefits of pathological cognitions to argue for further indirect epistemic benefits of psychedelic therapy. He echoes Bortolotti's argument that epistemic functionality and psychosocial functionality are deeply intertwined in humans. Bortolotti points out that some of the main ways in which humans gain knowledge involve engaging with the world, exploring, talking to other people, exposing one's ideas to scrutiny, and so on. Pathologies such as anxiety, depression, and addiction tend to decrease people's propensity to engage with the world in this way. Thus, Letheby (2016) argues that when psychedelics reduce symptoms of these pathologies, this is likely to improve patients' epistemic functionality too. He proposes that a similar effect might be observed in healthy subjects, citing findings from MacLean, Johnson, and Griffiths (2011) that psilocybin-induced mystical experiences can increase the personality domain of Openness to Experience-plausibly a pro-epistemic trait-for up to 14 months (Letheby, 2016).

Lavazza (2017) has contested Letheby's attribution of epistemic benefits to psychedelic states, suggesting that the benefits in question seem "more motivational than epistemic" (p. 250). However, he offers no explicit argument for this claim. He also suggests that any self-knowledge gained under psychedelic experience is only knowledge about what the self is like during psychedelic experience, not knowledge of the self "in its real environment" (Lavazza, 2017)

Finally, Pittaway (2018) suggests that, by altering attention and de-familiarizing the world, allowing us to see things anew, psychedelics can foster a type of 'philosophical perception' similar to that pursued in the mystical and contemplative practices typical of ancient Greek philosophy. In other words, for Pittaway (2018), there is a strong similarity between psychedelic consciousness and the distinctively philosophical consciousness prized by the ancients who practiced philosophy as a way of life (Nicolas Langlitz (2016) discusses similar themes in his reflection on whether psychedelics can have a place in $21^{\text {st }}$-century philosophy.). Pittaway suggests that the phrase "to learn healing knowledge", coined by Sobiecki (2012) in his discussion of indigenous South African use of psychoactive plants, aptly characterises this philosophically relevant epistemic benefit that can be induced by psychedelics.

\section{ETHICS}

Three distinct issues concerning ethics and psychedelics have been attracting philosophical attention. One concerns the ethical implications of the epistemological issues just discussed: How much, if at all, does it matter whether psychedelic experiences involve real insights or "comforting delusions"? The second concerns the broader question: under what circumstances it is morally acceptable to administer such an unusual and potentially transformative intervention? The third concerns whether psychedelics themselves might function as effective agents of moral enhancement-i.e. the promotion of beneficial moral capacities or dispositions in individuals, by broadly biological or broadly technological means-and what follows, if so.

\section{The ethics of belief}

It is one thing to ask whether psychedelic experiences afford genuine insights or not, and another thing to ask whether it matters. Philosophical discussions of psychedelic-assisted psychotherapy (henceforth "psychedelic therapy") have explored the question: should we care about the epistemic status of this intervention? Despite disagreeing on what that status is, both Letheby (2016) and Lavazza (2017) agree that we should care. Lavazza (2017) contrasts "realistic" methods for promoting well-being, that involve gaining genuine knowledge of reality, with "unrealistic" methods that involve misrepresentation. According to him, psychedelic therapy belongs in the latter class, and therefore warrants caution (Lavazza, 2017). In a similar vein, Letheby (2016) cites Nozick's (1974/2013) “Experience Machine" thought experiment, as well as discussing Pascal's Wager (Pascal, $1670 / 2006$ ), to argue that we should be reluctant to embrace a therapeutic modality with significant unmitigated epistemic costs. For Letheby (2016), the main costs to worry about are the promotion of non-naturalistic metaphysical beliefs in a divine Ground of Being or cosmic consciousness. However, despite agreeing on the normative claim that the epistemic status of psychedelic therapy matters, Letheby (2016) ultimately comes out in its favour: he argues that the adoption of non-naturalistic beliefs is not an inevitable result of psychedelic therapy, and when it does occur, is offset by the naturalistically acceptable epistemic benefits detailed above (e.g. the acquisition of various kinds of knowledge by acquaintance, and various indirect benefits; see the "Knowledge" section). 
On the other hand, Flanagan and Graham (2017) have argued that the epistemic status of the psychedelic experience is relatively unimportant compared to its capacity to help people live good, happy, flourishing lives (Flanagan 2017, 2018; Flanagan \& Graham, 2017). This is part of their broader project to protest the pathologization of various mental states on epistemic grounds. Flanagan and Graham point out that there is no "clear, precise, or firm link" (2017, p. 293) between epistemic accuracy and mental health; neither is necessary nor sufficient for the other. As such, even though they conceive of psychedelic mystical experiences as "metaphysical hallucinations", they argue that the induction and pursuit of such hallucinations can be ethically justified on the basis of their apparent psychological, existential, and perhaps even ethical benefits (cf. Flanagan, 2017, 2018).

Similarly, Greif and Šurkala (2020) argue that we ought not be concerned about epistemic risks stemming from the use of psilocybin in compassionate psychedelic therapy (PT). They disagree with Letheby's (2016) naturalistic position that psychedelic therapy involves comforting delusions that are epistemically harmful. For Greif and Surkala, the permissibility of compassionate PT can be evaluated on a risk/benefit ratio, and against other medical interventions (e.g., palliative care). These authors note that there is no scientific evidence that suggests the acquisition of nonnaturalistic beliefs is part of the causal mechanism of psychedelic therapy. Even if there were such evidence, however, they argue that this would not be sufficient to deem psychedelic therapy unethical (Greif \& Šurkala, 2020). Their main contention is that naturalism is a controversial stance in the highly contested field of philosophical metaphysics, and as such, has no business dictating medical practice. According to Greif and Šurkala, even if psychedelic therapy did demonstrably impose non-naturalistic beliefs on patients, in order to know that this amounted to epistemic harm, we would need to know that naturalism is true. However, since (they argue) we do not know the truth of naturalism, we do not know that the acquisition of nonnaturalistic beliefs would constitute epistemic harm; thus, this possibility does not provide compelling grounds for concern about psychedelic therapy. This is the major difference between their position and that of Letheby (2016), who assumes that the truth of naturalism is, indeed, an object of knowledge.

Finally, McMillan (2020) responds to epistemic concerns about psychedelic therapy by drawing on ideas from hedonistic moral theories, arguing that in cases of extreme suffering, hedonic benefits outweigh epistemic risks. He also echoes Letheby's contention that the epistemic profile of psychedelic therapy may be better than it initially appears.

From this brief overview, we can see that questions about epistemic ethics and epistemology itself are deeply intertwined. Some argue that psychedelics impose misrepresentations and cognitive distortions that amount to epistemic harm. Others argue that evidence for the therapeutic and transformative effects of psychedelics outweighs their potential epistemic risks.

\section{Enhanced consent}

Smith and Sisti (2020) have raised the important question: Under what circumstances is it ethical to administer an intervention that can induce unusual, and potentially radically transformative, experiences? These authors focus specifically on psychedelic-induced mystical experiences, in which subjects commonly describe a "sense of new, ineffable knowledge, feelings of unity and connection and encounters with 'deep' reality or God” (Smith \& Sisti, 2020, p. 1). Smith and Sisti cite studies suggesting that these specific types of experiences may mediate lasting changes to subjects' attitudes, beliefs, and personality (Carhart-Harris et al., 2018; Davis et al., 2020; Erritzoe et al., 2018; Nour, Evans, \& Carhart-Harris, 2017). As such, they draw on clinical research to argue that an "enhanced consent" process is ethically required in psychedelic therapy due to the unusual features of this treatment.

Smith and Sisti propose three potential categories of effects that are unique to psilocybin and entail ethical requirements that go beyond what is typically prescribed for psychotropic medications (e.g., SSRIs, antipsychotics). First, psilocybin may elicit undesirable changes to subjects' beliefs, values, and personalities; for example, "non-spiritual, agnostic or atheist patients may take the development of a newfound sense of spirituality or belief in God to be a loss if it is incongruent with their prior values or if it is disruptive to relationships with others" (Smith \& Sisti, 2020, p. 3). (Here, there is a connection with the issues of epistemic ethics discussed in the previous sub-section.) Second, psilocybin may pose various mental health risks; for example, intense acute episodes of anxiety, lasting psychotic reactions, and trauma re-exposure due to the reliving of traumatic memories. Third, the use of therapeutic touch in psychedelic therapy can blur ethical boundaries, particularly when subjects are in a vulnerable state of mind; for example, subjects can unexpectedly change their mind about whether or not they would like therapeutic touch during the psychedelic experience.

Smith and Sisti describe standard consent procedures as more straightforward, since in the cases of most psychiatric pharmaceuticals, side-effects can be described quickly and understood easily, such as dizziness, nausea, and weight gain. For them, the peculiar side-effects of psilocybin call for a more comprehensive consent procedure:

\footnotetext{
"In general, the fundamental elements of disclosure are the nature of the procedure, the risks and potential benefits and what alternatives may be available. While debate continues about the specificity regarding these elements in various contexts, there is consensus that the standards vary according to context and the intervention in question. For instance, standards for invasive surgery are higher than those for blood draw" (Smith \& Sisti, 2020, p. 3).
}

Other reasons for enhanced consent include their contention that little is known about the neural mechanisms by which psilocybin works in the brain, making it difficult to explain its effects on cognition (Smith \& Sisti, 2020). Smith 
and Sisti do acknowledge that, in current practice, the potential for distressing or transformative experiences is discussed in preparatory sessions. However, they suggest that these sessions be extended into the actual consent process while "offering recurrent opportunity [sic] to improve subject understanding and achieve enhanced consent" (2020, p. 3).

Finally, these authors emphasize the importance of future research. As psilocybin transitions from controlled clinical settings to clinical practise, ethical challenges will emerge that change the nature of the intervention and require critical evaluation. Thus, avenues for future research should include understanding how psilocybin elicits personal transformation and developing standardized protocols for informed consent procedures across psychedelic studies (Smith \& Sisti, 2020).

\section{Psychedelic moral enhancement}

The third ethical issue concerns the putative use of psychedelics for purposes of moral enhancement: Might psychedelics function as effective agents of moral enhancement? If so, under what circumstances is it ethical to administer them as such? Interest in moral enhancement (or moral bioenhancement) techniques is motivated by the contention that humans lack the moral capacity to respond appropriately to global issues and social inequalities in the face of rapid technological advancements (Ballesteros, 2019; Hidalgo, 2018; Schermer, 2007; Tennison, 2012). One ground for this concern is that deep-rooted prejudiced attitudes discourage cosmopolitan relations between people (Hidalgo, 2018; see also Schermer, 2007). Several authors have discussed moral neuroenhancement and various putative "neuroenhancers" for their potential to augment not only moral capacities, but also morally relevant cognitive capacities, such as empathy, fairness, and altruism (Ahlskog, 2017, Earp, 2018; Tennison, 2012). As such, some have suggested that psychedelics may be a viable way to improve individuals' moral character and cognition (Earp, 2018; cf.; Ahlskog, 2017; Tennison, 2012).

Some draw on psychedelic evidence to suggest that psychedelics durably increase prosocial behaviour, empathy, and the personality trait of Openness to Experience (Ahlskog, 2017; Ballesteros, 2019; Earp, 2018; Tennison, 2012). Earp (2018) discusses psychedelics as a promising alternative to currently available "smart drugs", gene therapies, and brain stimulation devices. He considers the latter as "onedimensional interventions into specific capacities" (Earp, 2018 , p. 16) that do not target a broader moral domain. He also notes that such interventions may not successfully "tweak" an individual cognitive capacity (e.g., empathy), given the complex and interconnected cognitive architecture of the brain. As such, Earp proposes that psychedelics might enhance moral capacities in a "global" and "flexible" way, allowing people to respond to different kinds of situations. In a similar vein, Ahlskog (2017) argues that directly modulating empathy alone may have adverse effects, such as unintentional empathetic responses, which may compromise autonomy (see also Ballesteros, 2019). However, rather than directly augmenting moral and prosocial motivations, he argues, a more effective route to developing higher moral values and altruistic behaviours may lie in "decreasing selfinterest". Ahlskog cites evidence from LSD and psilocybin research that links phenomenological reports of a diminished sense of self with neural correlates of self-awareness, and proposes that psychedelics diminish self-interest, "in a quite literal sense, rather than as a by-product of for example increases in empathy" (p. 368).

Similarly, Millière et al. (2018) have considered the possible link between interruptions of self-consciousness and prosocial behaviours induced by psychedelics, and ask whether temporary selfless states might promote selflessness in the moral sense. They argue that further research is required to confirm this relationship and urge caution in conflating selfless states with 'selflessness' as a moral construct (Millière et al., 2018).

Finally, Ballesteros (2019) discusses psychedelic moral enhancement in the context of environmental and technological ethics. She draws on the work of Günther Anders to argue that humans are morally blind to their obligations resulting from technological advances and associated ecological challenges. According to Ballesteros, psychedelic mysticism can result in enhanced moral faculties. She cites phenomenological reports of self-transcendence and feelings of interconnection with others and nature, as well as studies providing evidence of increases in prosocial and altruistic behaviors lasting up to 14 months post-psilocybin (Griffiths et al. 2008, 2011). Thus, Ballesteros suggests psychedelics can "widen" moral capacities and may thereby help us overcome our moral blindness.

\section{RELIGION AND SPIRITUALITY}

The fourth and final line of inquiry we will discuss is motivated by the broader philosophical project to naturalize spirituality, predicated on the idea that there may be religious and spiritual practices or attitudes that do not require a commitment to supernaturalistic or non-naturalistic beliefs (Letheby, 2017; Steinhart, 2018b). Some psychedelic subjects report transformative experiences of self-loss, connectedness, and profound meaning, in the apparent absence of nonnaturalistic metaphysical content (Letheby, 2017; Steinhart, 2018b). As such, some philosophers have drawn on psychedelic science to develop empirically informed accounts of naturalistic forms of spirituality or religion.

Steinhart (2018a) argues that religious naturalism must prescribe practices that embody genuinely religious ways of living in the natural world. Entheogenic (i.e., psychedelicbased) religions, he claims, fit the naturalistic bill because they involve using psychedelics to induce spiritual experiences without requiring non-naturalistic beliefs. Steinhart (2018b) proposes that psychedelics are "technologies" for achieving spiritual self-realization - "the existential unification of the self with nature" (p. 343), in line with the concept of eudaimonia, or human flourishing. He points to the Mystical Experience Questionnaire used in much psychedelic research 
as a way to examine the relationship between phenomenological reports of religious experiences (e.g., a connectedness with all living things) and neural correlates of self-related states. He draws on evidence from this research that such existential unification "depends on changes in [specific] neural networks in the brain" (2018b, p. 349). For Steinhart this supports psychedelics' potential as tools for developing forms of religious practice compatible with naturalism.

Letheby (2017) raises the important question: Can psychedelics help us find solutions to the existential crisis emerging from a scientific and naturalistic worldview? Flanagan and Caruso (2017) contend that a distinctive neuroexistential crisis, emerging from neuroscientific advancements, has shifted humanity's self-conception towards a meaningless and disenchanted scientific image. As Letheby puts it, "with every new stride in the neuroscientific mapping of the material bases of decision making, reward, emotions, and so on, this [disenchanted, naturalistic] reality becomes ever more palpable" (2017, p. 625). Letheby (2017) proposes that psychedelics may play a practical role in the naturalizing spirituality project and act as an "existential medicine", by facilitating a sense of meaning in life and revealing the conditions under which humans can experience eudaimonia. He cites Carhart-Harris et al.'s (2014) neuroimaging findings connecting psilocybin-induced experiences of self-transcendence, broadening of perspectives, and interconnectedness, to reduced activity in the default mode network (DMN)-a system of brain structures involved in self-representation. Letheby proposes that these "neurocognitive systems" may generate an illusory sense of self that "[constrains] cognition and consciousness in accordance with representations of the goals, priorities, and predicaments of that self' (2017, p. 639) causing existential anxiety. For him, these findings suggest that what is central to psychedelic therapy is disruption to the sense of self, leading to changes in perspectives and attention, wonder and awe, and appreciation of the natural world-not nonnaturalistic metaphysical beliefs.

Despite differences of approach, Letheby (2017) and Steinhart (2018a, 2018b) agree that psychedelics afford transformative experiences that can result in perspectival and existential changes that are paradigmatic for developing spiritual naturalism, and moreover, provide practical ways to overcome existential distress. For both, naturalistically acceptable religious and spiritual experiences induced by psychedelics centrally involve transcendence of the sense of self and feelings of interconnection with nature.

For a relevant, anthropological essay on mystic materialism in the revival of psychedelic research, see Langlitz (2012). For a Foucauldian argument that psychedelic consumption can be a genuine spiritual practice, see Stokkink (2015).

\section{CONCLUSION}

Renewed scientific interest in serotonergic psychedelics has prompted intriguing discussions at the intersection of academic philosophy and psychedelic science. We have provided an overview of four emerging lines of research that have gained considerable traction in the last decade: philosophy of mind, epistemology, ethics, and religious/spiritual naturalism. Psychedelic evidence has contributed to ongoing debates about self-consciousness. The psychedelic experience itself has been subjected to epistemological analysis. Various authors have examined ethical issues concerning psychedelic use and possible moral enhancement applications of psychedelics. Finally, others have enlisted psychedelic evidence in the service of naturalistic spirituality and religious naturalism.

\section{ACKNOWLEDGEMENTS}

Dr Letheby's contribution to this research was partially supported by the Australian Government through the Australian Research Council's Discovery Projects funding scheme (project DP190101451). The views expressed herein are those of the authors and are not necessarily those of the Australian Government or Australian Research Council. Funding for Ms Mattu's contribution to this work was provided by The Rotman Institute of Philosophy and the Richard A. Harshman scholarship through the Department of Philosophy and Department of Psychology at Western University.

\section{REFERENCES}

Ahlskog, R. (2017). Moral enhancement should target self-interest and cognitive capacity. Neuroethics, 10, 363-373.

Ballesteros, V. (2019). Applied mysticism: A drug-enabled visionary experience against moral blindness. Zygon, 54(3), 731-755.

Bayne, T., \& Carter, O. (2018). Dimensions of consciousness and the psychedelic state. Neuroscience of Consciousness, 4(1), niy008.

Billon, A., \& Kriegel, U. (2015). Jaspers' dilemma: The psychopathological challenge to subjectivity theories of consciousness. In R. J. Gennaro (Ed.), Disturbed consciousness: New essays on psychopathology and theories of consciousness (pp. 29-54). Cambridge, MA: MIT Press.

Bortolotti, L. (2015). The epistemic innocence of motivated delusions. Consciousness and Cognition, 33, 490-499.

Bortolotti, L. (2020). The epistemic innocence of irrational beliefs. Oxford University Press.

Brogaard, B. (2013). Serotonergic hyperactivity as a potential factor in developmental, acquired and drug-induced synesthesia. Frontiers in Human Neuroscience, 7(657).

Brogaard, B., \& Gatzia, D. E. (2016a). What can neuroscience tell us about the hard problem of consciousness? Frontiers in Neuroscience, 10(395).

Brogaard, B., \& Gatzia, D. E. (2016b). Psilocybin, lysergic acid diethylamide, mescaline, and drug-induced synesthesia. In V. R. Preedy (Ed.), Neuropathology of drug addictions and substance misuse (Vol. 2, pp. 890-905). Academic Press.

Carhart-Harris, R. L. (2019). How do psychedelics work? Current Opinion in Psychiatry, 32(1), 16-21. 
Carhart-Harris, R. L., Bolstridge, M., Day, C. M. J., Rucker, J., Watts, R., Erritzoe, D. E., Kaelen, M., Giribaldi, B., Bloomfield, M., Pilling, S., \& Rickard, J. A. (2018). Psilocybin with psychological support for treatment-resistant depression: Sixmonth follow-up. Psychopharmacology, 235(2), 399-408.

Carhart-Harris, R. L., \& Friston, K. J. (2019). REBUS and the anarchic brain: Toward a unified model of the brain action of psychedelics. Pharmacological Reviews, 71(3), 316-344.

Carhart-Harris, R. L., Leech, R., Hellyer, P. J., Shanahan, M., Feilding, A., Tagliazucchi, E., Chialvo, D. R., \& Nutt, D. (2014). The entropic brain: A theory of conscious states informed by neuroimaging research with psychedelic drugs. Frontiers in Neuroscience, 8(2), 1-22.

Davis, A. K., Barrett, F. S., \& Griffiths, R. R. (2020). Psychological flexibility mediates the relations between acute psychedelic effects and subjective decreases in depression and anxiety. Journal of Contextual Behavioral Science, 15, 39-45.

Earp, B. D. (2018). Psychedelic moral enhancement. Royal Institute of Philosophy Supplements, 83, 415-439.

Erritzoe, D., Roseman, L., Nour, M. M., MacLean, K., Kaelen, M., Nutt, D. J., \& Carhart- Harris, R. L. (2018). Effects of psilocybin therapy on personality structure. Acta Psychiatrica Scandinavica, 138(5), 368-378.

Fink, S. B. (2020). Look who's talking! Varieties of ego-dissolution without paradox. Philosophy and the Mind Sciences, 1(1), 1-36.

Flanagan, O. (2017). Consciousness and the moral sciences: Positive metaphysical hallucinations. In K. Almqvist \& A. Haag (Eds.), The return of consciousness: A new science on old questions (pp. 335-348). Axess Publishing.

Flanagan, O. (2018). Hallucinating oneness: Is oneness true or just a positive metaphysical illusion? In P. J. Ivanhoe (Ed.), The oneness hypothesis: Beyond the boundary of self (pp. 269-284). Columbia University Press.

Flanagan, O., \& Caruso, G. D. (2017). Neuroexistentialism: ThirdWave existentialism. In O. Flanagan \& G. D. Caruso (Eds.), Neuroexistentialism: Meaning, morals and purpose in the age of neuroscience (pp. 1-36). Oxford, UK: Oxford University Press.

Flanagan, O., \& Graham, G. (2017). Truth and sanity: Positive illusions, spiritual delusions, and metaphysical hallucinations. In J. Poland \& S. Tekin (Eds.), Extraordinary science and psychiatry: Responses to the crisis in mental health research (pp. 293-313). MIT Press.

Fortier-Davy, M., \& Millière, R. (2020). The multi-dimensional approach to drug-induced states: A commentary on Bayne and carter's "dimensions of consciousness and the psychedelic state". Neuroscience of Consciousness, 6(1), niaa004.

Gallimore, A. R. (2015). Restructuring consciousness-the psychedelic state in light of information theory. Frontiers in Human Neuroscience, 9(346).

Gandy, S. (2019). Psychedelics and potential benefits in "Healthy Normals": A review of the literature. Journal of Psychedelic Studies, 3(3), 280-287.

Graham, G., \& Stephens, G. L. (Eds.) (1994). Philosophical psychopathology. Cambridge, MA: MIT Press.

Greif, A., \& Šurkala, M. (2020). Compassionate use of psychedelics. Medicine, Health Care, and Philosophy, 23, 485-496.

Griffiths, R. R., Johnson, M. W., Carducci, M. A., Umbricht, A., Richards, W. A., Richards, B. D., Cosimano, M. P., \& Klinedinst, M. A. (2016). Psilocybin produces substantial and sustained decreases in depression and anxiety in patients with life-threatening cancer: A randomized double-blind trial. Journal of Psychopharmacology, 30(12), 1181-1197.

Griffiths, R. R., Johnson, M. W., Richards, W. A., Richards, B. D., McCann, U., \& Jesse, R. (2011). Psilocybin occasioned mysticaltype experiences: Immediate and persisting dose-related effects. Psychopharmacology, 218(4), 649-665.

Griffiths, R. R., Richards, W. A., Johnson, M. W., McCann, U. D., \& Jesse, R. (2008). Mystical-type experiences occasioned by psilocybin mediate the attribution of personal meaning and spiritual significance 14 Months later. Journal of Psychopharmacology, 22(6), 621-632.

Griffiths, R. R., Richards, W. A., McCann, U., \& Jesse, R. (2006). Psilocybin can occasion mystical-type experiences having substantial and sustained personal meaning and spiritual significance. Psychopharmacology, 187(3), 268-283.

Grinde, B., \& Stewart, L. (2020). A global workspace, evolutionbased model of the effect of psychedelics on consciousness. Psychology of Consciousness: Theory, Research, and Practice, 7(3), 262-278.

Grof, S. (1975). Realms of the human unconscious: Observations from LSD psychotherapy. New York: Viking.

Henriksen, M. G., \& Parnas, J. S. S. (2019). Experiences without forme-ness? Reconsidering alleged counter examples from psychopathology and psychedelics. Thaumazein, 7, 6-20.

Hidalgo, J. (2018). Cosmopolitan moral enhancement. In J. Flanigan \& T. Price (Eds.), The ethics of ability and enhancement (pp. 173-196). New York: Palgrave Macmillan. Jepson Studies in Leadership.

Horváth, L., Szummer, C., \& Szabo, A. (2018). Weak phantasy and visionary phantasy: The phenomenological significance of altered states of consciousness. Phenomenology and the Cognitive Sciences, 17(1), 117-129.

Huxley, A. (2009). The doors of perception. Reprint. New York: HarperCollins. (Original work published 1954).

Jones, R. H. (2019). Limitations on the scientific study of druginduced mystical experiences. Zygon ${ }^{\circledR}, 54(3), 756-792$.

Jopling, D. A. (2001). Placebo insight: The rationality of insight-oriented psychotherapy. Journal of Clinical Psychology, 57(1), 19-36.

Kastrup, B. (2016). What neuroimaging of the psychedelic state tells us about the mind- body problem. Journal of Cognition and Neuroethics, 4(2), 1-9.

Kentridge, R. W., \& Brogaard, B. (2017). The functional roles of attention. In B. Nanay (Ed.), Current controversies in philosophy of perception (pp. 139-147). Taylor and Francis.

Langlitz, N. (2012). Neuropsychedelia: The revival of hallucinogen research since the decade of the brain. Berkeley: University of California Press.

Langlitz, N. (2016). Is there a place for psychedelics in philosophy?: Fieldwork in neuro and perennial philosophy. Common Knowledge, 22(3), 373-384.

Lavazza, A. (2017). Ways of being well: Realistic and unrealistic well-being. In L. Taddio \& K. W. Molin (Eds.), New perspectives on realism (pp. 237-252). Mimesis International.

Letheby, C. (2015). The philosophy of psychedelic transformation. Journal of Consciousness Studies, 22(9-10), 170-193.

Letheby, C. (2016). The epistemic innocence of psychedelic states. Consciousness and Cognition, 39, 28-37. 
Letheby, C. (2017). Naturalizing psychedelic spirituality. Zygon, 52(3), 623-642.

Letheby, C. (2020). Being for no-one: Psychedelic experience and minimal subjectivity. Philosophy and the Mind Sciences, 1(I), 126. https://doi.org/10.33735/phimisci.2020.I.47.

Letheby, C., \& Gerrans, P. (2017). Self unbound: Ego dissolution in psychedelic experience. Neuroscience of Consciousness, 2017(1), nix016.

MacLean, K. A., Johnson, M. W., \& Griffiths, R. R. (2011). Mystical experiences occasioned by the hallucinogen psilocybin lead to increases in the personality domain of openness. Journal of Psychopharmacology, 25(11), 453-1461.

McMillan, R. M. (2020). Prescribing meaning: Hedonistic perspectives on the therapeutic use of psychedelic-assisted meaning enhancement. Journal of Medical Ethics, 0, 1-5.

Metzinger, T. (2003). Being no one: The self-model theory of subjectivity. A bradford book. Cambridge, MA: MIT Press.

Millière, R. (2017). Looking for the self: Phenomenology, neurophysiology and philosophical significance of drug-induced ego dissolution. Frontiers in Human Neuroscience, 11(245).

Millière, R. (2020). The varieties of selflessness. Philosophy and the Mind Sciences, 1(I), 8, 1-41.

Millière, R., Carhart- Harris, R. L., Roseman, L., Trautwein, F. M., \& Berkovich- Ohana, A. (2018). Psychedelics, meditation, and self-consciousness. Frontiers in Psychology, 9(1475).

Nida-Rümelin, M., \& Conaill, D. O. (2019). Qualia: The knowledge argument. In E. N. Zalta (Ed.), The stanford encyclopedia of philosophy (Winter 2019 Edition). https://plato.stanford.edu/ archives/win2019/entries/qualia-knowledge/.

Nour, M. M., Evans, L., Nutt, D., \& Carhart-Harris, R. L. (2017). Psychedelics, personality and political perspectives. Journal of Psychoactive Drugs, 49(3), 182-191.

Nour, M. M., Evans, L., Nutt, D., \& Carhart- Harris, R. L. (2016). Egodissolution and psychedelics: Validation of the ego- dissolution inventory (EDI). Frontiers in Human Neuroscience, 10(269).

Nozick, R. (2013). Anarchy, state, and utopia. New York: Basic Books. (Original work published 1974).

O’Brien, G., \& Opie, J. (2015). A schizophrenic defense of a vehicle theory of consciousness. In R. J. Gennaro (Ed.), Disturbed consciousness (pp. 265-292). Cambridge, MA: MIT Press.

Osmond, H. (1971). Philosophical aspects of psychedelics. Internationale Zeitschrift fur klinische Pharmakologie, Therapie, und Toxikologie. International Journal of Clinical Pharmacology, Therapy, and Toxicology, 5(1), 58-64.

Pahnke, W. N. (1963). Drugs and mysticism: An analysis of the relationship between psychedelic drugs and the mystical consciousness: A thesis. (Doctoral dissertation, Harvard University). Multidisciplinary Association of Psychedelic Studies.

Pascal, B. (2006). Pascal's Pensées (eBook Edition). New York, NY: E.P. Dutton \& CO, INC. (Original work was published 1670). https://www.gutenberg.org/ebooks/18269.

Pittaway, D. A. (2018). "To learn healing knowledge": Philosophy, psychedelic studies and transformation. South African Journal of Philosophy, 37(4), 438-451.
Richards, W. A. (2015). Sacred knowledge: Psychedelics and religious experiences. Columbia University Press.

Russell, B. (1910). Knowledge by acquaintance and knowledge by description. Proceedings of the Aristotelian Society, 11, 108-128.

Schermer, M. H. N. (2007). Brave new world versus island utopian and dystopian views on psychopharmacology. Medicine, Health Care and Philosophy, 10(119), 119-128.

Sebastián, M. A. (2020). Perspectival self-consciousness and egodissolution: An analysis of (some) altered states of consciousness. Philosophy and the Mind Sciences, 1(I), 1-27. https://doi. org/10.33735/phimisci.2020.I.44.

Shanon, B. (2001). The divine within. Journal of Consciousness Studies, 8(2), 91-95.

Shanon, B. (2010). The epistemics of ayahuasca visions. Phenomenology and the Cognitive Sciences, 9(2), 263-280.

Smith, H. (1964). Do drugs have religious import? Journal of Philosophy, 61(18), 517-530.

Smith, H. (2003). Cleansing the doors of perception: The religious significance of entheogenic plants and chemicals. Reprint. Boulder: Sentient Publications. (Original work published 2000).

Smith, W. R., \& Sisti, D. (2020). Ethics and ego dissolution: The case of psilocybin. Journal of Medical Ethics, 0, 1-8.

Smythies, J. R. (1953). The mescaline phenomena. British Journal for the Philosophy of Science, 3(12), 339-347.

Sobiecki, J. F. (2012). Psychoactive ubulawu spiritual medicines and healing dynamics in the initiation process of southern Bantu diviners. Journal of Psychoactive Drugs, 44(3), 216-223.

Steinhart, E. (2018a). Religion after naturalism. In J. L. \& P. Draper (Eds.), Renewing philosophy of religion (pp. 63-78). New York: Oxford University Press.

Steinhart, E. (2018b). Practices in religious naturalism. In D. Crosby \& J. Stone (Eds.), Routledge handbook of religious naturalism (pp. 341-351). New York: Routledge.

Stokkink, P. (2015). Psychedelics as a practice of truth: A foucauldian argument. In J. H. Ellens \& T. B. Roberts (Eds.), The psychedelic policy quagmire: Health, law, freedom, and society (pp. 177-202). Santa Barbara, CA: Praeger, ABC-CLIO, LLC.

Szummer, C., Almási, A., \& Fruzsina, I. (2019). Dreaming consciousness in phenomenology and depth psychology. Journal of Experiential Psychotherapy, 22(3), 3-11.

Szummer, C., Horváth, L., Szabó, A., Frecska, E., \& Orzói, K. (2017). The hyperassociative mind: The psychedelic experience and merleauponty's “wild being”. Journal of Psychedelic Studies, 1(2), 55-64.

Tennison, M. (2012). Moral transhumanism: The next step. Journal of Medicine and Philosophy, 37(4), 405-416.

Wheeler, S. W., \& Dyer, N. L. (2020). A systematic review of psychedelic-assisted psychotherapy for mental health: An evaluation of the current wave of research and suggestions for the future. Psychology of Consciousness: Theory, Research, and Practice, 7(3), 270-315. https://doi.org/10.1037/cns0000237.

Zahavi, D., \& Kriegel, U. (2015). For-me-ness: What it is and what it is not. In D. O. Dahlstrom, A. Elpidorou \& W. Hopp (Eds.), Philosophy of mind and phenomenology: Conceptual and empirical approaches (pp. 48-66). New York: Routledge.

Open Access. This is an open-access article distributed under the terms of the Creative Commons Attribution-NonCommercial 4.0 International License (https:// creativecommons.org/licenses/by-nc/4.0/), which permits unrestricted use, distribution, and reproduction in any medium for non-commercial purposes, provided the original author and source are credited, a link to the CC License is provided, and changes - if any - are indicated. 